\title{
Da noção de subjetividade de Benveniste à leitura como ato enunciativo
}

\section{From the concept of subjectivity of Benveniste to reading as an act of enunciation}

https://doi.org/10.34112/2317-0972a2017V35n69p87-102

\section{Carina Fior Postingher Balzan ${ }^{1}$}

RESUMO: O propósito deste artigo é, a partir da noção de subjetividade pensada por Émile Benveniste, abordar a leitura como um ato enunciativo. A reflexão teórica construída, com base nos artigos de Benveniste e em estudiosos da teoria da enunciação, como Flores, Barbisan, Teixeira e Normand, permite associar a leitura ao ato do sujeito que, de maneira individual, mobiliza a língua para enunciar-se. A subjetividade, na atividade da leitura, apresenta-se como a capacidade do leitor/locutor de apropriar-se da língua e atualizá-la, reconstituindo sentidos e posicionando-se no discurso como sujeito que diz eu.

PALAVRAS-CHAVE: Leitura; subjetividade; teoria da enunciação.

ABSTRACT: This article aims to approach the reading as an act of enunciation, from the notion of subjectivity thought by Emile Benveniste. The theoretical reflection constructed, based on the papers written by Benveniste and enunciation theory students, such as Flores, Barbisan, Teixeira and Normand, consents to associate reading with the act of the subject that, individually, mobilizes the language to enunciate. In the activity of reading, the subjectivity is presented as the capacity of the readers/speakers to appropriate and

1. Instituto Federal de Educação, Ciência e Tecnologia do Rio Grande do Sul - Câmpus Bento Gonçalves, Bento Gonçalves, RS, Brasil. Universidade de Caxias do Sul, Caxias do Sul, RS, Brasil. 
update the language, rebuilding meanings and positioning themselves in the speech as subject that says $I$.

KEYWORDS: Reading; subjectivity; enunciation theory.

É na linguagem e pela linguagem que o homem se constitui como sujeito; porque só a linguagem fundamenta na realidade, na sua realidade que é a do ser, o conceito de "ego".

O fundamento da subjetividade está no exercício da língua.

(BENVENISTE, 1995)

\section{CONSIDERAÇÕES INICIAIS}

Considerado o principal representante da teoria da enunciação, Émile Benveniste (1902-1976), com base nos preceitos estruturalistas de Saussure, desenvolveu um modelo de análise da língua especificamente voltado à enunciação, questionando os estudos linguísticos de sua época, centrados no princípio da imanência, os quais investigavam as regularidades do sistema, abstraindo toda a referência a elementos externos ao método.

Ao incluir no objeto da linguística questões como subjetividade, referência, dêixis, entre outras, Benveniste explora as relações da língua não apenas como sistema combinatório, mas como linguagem assumida por um sujeito. Na proposição da enunciação, o teórico aborda fenômenos relativos ao uso da língua e a quem fala, instaurando uma instância única e irrepetível, constituída pelas categorias de pessoa, tempo e espaço.

O intuito deste artigo é, partindo da noção de subjetividade pensada por Benveniste, abordar a leitura como um ato de enunciação. Não temos a pretensão de propor um modelo de análise do discurso escrito, mas buscamos apresentar algumas considerações que permitam associar o fenômeno da leitura ao ato do sujeito que, de maneira individual, mobiliza a língua para enunciar-se. Para tanto, além dos artigos de Benveniste presentes em Problemas de linguística geral I e II, buscamos subsídios em estudiosos da teoria enunciativa, como Valdir do Nascimento Flores, Marlene Teixeira, Lecy Borges Barbisan e Claudine Normand, os quais, a partir de suas reflexões, nos ajudaram a construir esta abordagem.

A atividade da leitura pode ser explicada por várias perspectivas teóricas. Para a finalidade deste artigo, entendemos a leitura como um processo de construção de 
sentidos que se dá na inter-relação entre o leitor e o texto. Ou seja, o sentido não está no texto em si, como um dado pronto e imutável, mas também não é resultado da livre interpretação do leitor. $O$ sentido se estabelece a partir de um processo dinâmico, em que o leitor percebe os recursos linguísticos empregados pelo autor na construção do texto, na tentativa de interpretá-los, de compreendê-los, mobilizando, para isso, seus conhecimentos prévios (linguísticos, enciclopédicos, de mundo, etc.). É essa definição, em sentido amplo, que adotamos inicialmente para, ao longo do artigo, construir nossa abordagem da leitura sob a perspectiva enunciativa.

É fato que Benveniste, em seus escritos, não aborda explicitamente a questão da leitura, mas admite que a enunciação constitui um fenômeno complexo, ainda por ser explorado em suas múltiplas perspectivas. Em "O aparelho formal da enunciação" $(1970)^{2}$, Benveniste indica uma possibilidade a ser analisada - a da enunciação escrita -, na qual, acrescentamos, está implícito o ato da leitura:

[...] Seria preciso também distinguir a enunciação falada da enunciação escrita. Esta se situa em dois planos: o que escreve se enuncia ao escrever e, no interior de sua escrita, ele faz os indivíduos se enunciarem. Amplas perspectivas se abrem para a análise das formas complexas do discurso, a partir do quadro formal esboçado aqui. (BENVENISTE, 1989, p. 90).

Poucos pesquisadores aventuraram-se a explorar a questão da leitura a partir da teoria benvenistiana. Dentre eles, Flores e Teixeira (2005), na apresentação do livro Introdução à linguística da enunciação, autorizam essa proposta de estudo, ao reconhecer que a leitura é também um fenômeno enunciativo. De acordo com eles,

reconhecer isso implica levar em conta a assimetria atípica da cena enunciativa: a pessoa que interpreta um enunciado reconstrói seu sentido a partir de indicações nele presentes, mas nada garante que o que ela reconstrói coincida com as representações do enunciador. A relação intersubjetiva que se produz na leitura é sempre inédita. O sentido, longe de ser imanente, se apresenta como o resultado de um processo de apropriação do texto pelo leitor, que imprime a sua singularidade na experiência da leitura. (FLORES; TEIXEIRA, 2005, p. 8).

2. Todos os artigos de Benveniste citados neste texto fazem parte da obra Problemas de linguística geral I e II, citada nas referências. 
Este é o ponto de partida para a reflexão aqui apresentada. Para melhor estruturar nossa argumentação a respeito da leitura, entendida como ato enunciativo, primeiramente apresentamos alguns conceitos saussurianos que serviram de base à teoria da enunciação de Benveniste, os quais ele acaba por ampliar ou redefinir. Em seguida, apontamos a noção de subjetividade como determinante na concepção de sujeito falante, categoria indispensável à formulação da teoria da enunciação. Daí, passamos para a construção do sentido na linguagem, que reforça a ideia da língua posta em exercício por um locutor, para, por fim, tomando o aparelho formal da enunciação, conceber uma abordagem da leitura como um ato de apropriação da língua pelo sujeito que, ao enunciar-se, reconstitui sentidos e instaura, no discurso, as marcas de sua subjetividade.

\section{Do (Des)encontro entre Saussure e Benveniste}

Vários são os pontos de vista que buscam explicar a relação entre Ferdinand de Saussure e Émile Benveniste. Normand (2009), uma das maiores leitoras desses teóricos, em artigo intitulado "Saussure-Benveniste", apresenta cinco discursos que evocam essa relação: a) o da filiação, da transmissão, da "escola”, ou seja, a continuidade histórica do conhecimento transmitido de uma geração a outra, em que Saussure teria gerado Benveniste; b) o discurso da novidade, em que Benveniste agrega a subjetividade, o mundo e o discurso que se faz sobre ele à linguística, reatando com a filosofia e aproximando-se da psicologia social e da pragmática; c) o discurso da comparação, em que Saussure teria influenciado Benveniste, ao fornecer os princípios, os temas e o método, os quais foram aplicados por Benveniste em análises concretas "que transformaram (ou simplesmente enriqueceram) as descrições comparatistas”; d) o discurso em relação à interdisciplinaridade, em que Saussure delimita o objeto da Linguística, distinguindo-a das outras ciências, enquanto Benveniste se dirige aos sociólogos, filósofos e psicanalistas, convidando-os a se unirem em favor de uma "semiologia universal”; e) o discurso em relação à instituição universitária, na qual, ao mesmo tempo em que ambos receberam notoriedade certificada através de títulos, publicações e cargos, ambos vivenciaram uma solidão intelectual, inclusive entre os colegas, e produziram um grande volume de manuscritos, alguns ainda por publicar.

Ao discutir esses pontos de vista, que oscilam entre continuidade e superação, Normand (2009, p. 198) prefere falar em "encontro": "Benveniste encontrou Saussure no que pôde conhecer de seus escritos”. Flores (2013, p. 50) reafirma essa ideia de 
encontro: "Benveniste toma Saussure como ponto de partida, mas não se encerra nele. Benveniste mantém, altera e mesmo nega Saussure para construir sua visão da linguagem. Então, é de um encontro que se trata, no sentido mais amplo da palavra”.

Em seus artigos, compilados em Problemas de linguística geral I e II, Benveniste deixa explícitos os pressupostos teóricos que formaram a base de suas reflexões sobre a linguagem. É da noção de língua enquanto sistema de signos de Saussure, apresentado no Curso de linguística geral ${ }^{3}$, que o autor parte para problematizar as noções de signo, de valor, de fala, etc., a fim de propor a chamada teoria da enunciação.

Enquanto, para Saussure, a relação entre significante e significado é arbitrária, Benveniste (1995, p. 55) pensa essa relação como necessária: "Um dos componentes do signo, a imagem acústica, constitui o seu significante; a outra, o conceito, é o seu significado. Entre o significante e o significado, o laço não é arbitrário; pelo contrário, é necessário". Para ele, o arbitrário só existe em relação com o fenômeno ou objeto material e não intervém na constituição própria do signo. Diz Benveniste (1995, p. 56): “o que é arbitrário é que um signo, mas não outro, se aplica a determinado elemento da realidade, mas não a outro".

Segundo Flores (2013, p. 53), a noção de arbitrário de Benveniste, vista como aplicação de um termo à realidade, aproxima-se do campo da contingência de uma língua, enquanto a relação significante/significado aproxima-se do campo da necessidade: "é necessário que se tenha a relação significante/significado para que exista uma língua; é contingente a relação à realidade que o signo possa fazer”.

A redefinição de signo de Benveniste acaba por reforçar a noção de valor de Saussure, pois reafirma a noção imanentista e não referencialista da língua, já que o valor é uma propriedade interna ao sistema linguístico e necessária a ele. Sobre isso afirma Flores (2013, p. 59):

A relatividade dos valores é a melhor prova de que dependem estreitamente uns dos outros na sincronia de um sistema sempre ameaçado, sempre restaurado. Isso se deve a que todos os valores são de oposição e não se definem a não ser pela sua diferença. [...] $\mathrm{O}$ caráter absoluto do signo linguístico assim entendido comanda, por sua vez, a necessidade dialética dos valores em constante oposição, e forma o princípio estrutural da língua.

3. A obra Curso de linguística geral foi publicada em 1916, após a morte de Saussure. Os editores, Albert Sechehaye e Charles Bally, organizaram-na a partir de notas dos cadernos de alunos de Saussure sobre três cursos ministrados pelo mestre na Universidade de Genebra. 
Para Benveniste, o significado do signo linguístico está relacionado à noção de uso da língua. Ou seja, o valor, inerente ao sistema, resulta da influência que o uso tem sobre esse sistema (FLORES; TEIXEIRA, 2009). Pode-se dizer, assim, que o signo somente adquire existência em um contexto de uso da língua.

Significar é ter um sentido, nada mais. E este sim ou não só pode ser pronunciado por aqueles que manuseiam a língua, aqueles para os quais esta língua é a língua e nada mais. Nós erigimos, desta forma, a noção de uso e de compreensão da língua como um princípio de discriminação, um critério. É no uso da língua que um signo tem existência; o que não é usado não é signo; e fora do uso o signo não existe. Não há estágio intermediário; ou está na língua, ou está fora da língua, "tertium non datur". (BENVENISTE, 1989, p. 227, grifos do autor).

O ponto em que Benveniste opta por trilhar um caminho diferente ao de Saussure, e aí podemos falar de "desencontro", é que a noção de signo desenvolvida por Benveniste inclui o uso que dele faz o falante. Segundo Flores (2013, p. 63), “[...] diferentemente de Saussure, que pensava a língua como distinta da fala, Benveniste pensa a língua constituída, a um só tempo, pelo semiótico e pelo semântico”. Nessa perspectiva, língua e fala não se opõem, mas se complementam: a língua comporta a fala e vice-versa.

A separação entre língua e fala, preconizada por Saussure, foi necessária para o estabelecimento de um objeto científico para a linguística, em face da falta de metodologia dos estudos da época, como explicam Flores e Barbisan (2009, p. 10, grifo dos autores):

A percepção de que a linguagem é um todo multiforme aliada à preocupação em construir os princípios da ciência linguística - que necessitava definir um objeto único e autônomo para análise - fizeram com que o conceito de língua se tornasse o ponto de partida das reflexões saussurianas contidas no CLG.

Enquanto a língua é, para Saussure, homogênea, vista como sistema, como norma para todas as manifestações da linguagem, passível, portanto, de ser estudada cientificamente, a fala é a utilização da língua, individual, heterogênea, de caráter criador e livre. 
A língua não constitui, pois, uma função do falante: é o produto que o indivíduo registra passivamente; não supõe jamais premeditação, e a reflexão nela intervém somente para a atividade de classificação [...] A fala é, ao contrário, um ato individual de vontade e inteligência, no qual convém distinguir: $1^{\mathrm{o}}$ - as combinações pelas quais o falante realiza o código da língua no propósito de exprimir seu pensamento pessoal; $2^{\circ}$ - o mecanismo psicofísico que lhe permite exteriorizar essas combinações. (SAUSSURE, 2012, p. 45).

Saussure prioriza a língua, recortando-a como objeto de análise; Benveniste, partindo da análise formal, como Saussure preconizou, dá uma atenção especial ao sentido, voltando-se para o discurso, para a linguagem. Benveniste, questionando a linguística de seu tempo, centrada na forma, resgata o sentido e, por meio de uma metodologia de análise da forma, estabelece um novo campo: o discurso (FLORES; BARBISAN, 2009).

Assim como para Saussure, para Benveniste continuam a existir dois níveis de linguagem, o semiótico e o semântico, mas entendidos não mais de maneira dissociada. A noção de relação entre elementos é mantida, constituindo paradigmas e sintagmas, mas o signo é ressignificado, o sentido passa a ter destaque, e o sujeito falante, relegado a segundo plano na proposta saussuriana, torna-se o centro de referência para a construção do sentido no discurso.

\section{DA RELAÇÃO EU-TU COMO FUNDANTE DA SUBJETIVIDADE}

Uma das noções pensadas por Benveniste que mais amplia a reflexão de Saussure sobre a linguagem é a noção de subjetividade, analisada em profundidade nos artigos "Da subjetividade na linguagem" (1958) e "A linguagem e a experiência humana” (1965). É Benveniste quem retoma o sujeito falante e o eleva à categoria indispensável à formulação de sua teoria da enunciação.

Isso não significa que Saussure tenha desprezado o sujeito falante de sua concepção teórica; apenas, por uma escolha metodológica, como já apontamos, prioriza a língua como objeto de estudo da linguística. Para o teórico, cabe ao sujeito falante a parte executiva da linguagem, a fala (parole), que é sempre um ato individual de vontade e inteligência, e dela o indivíduo é sempre senhor (SAUSSURE, 2012).

Saussure distingue claramente língua de fala, mas afirma que existe entre elas uma relação de interdependência na constituição da linguagem: 
Sem dúvida, esses dois objetos estão estreitamente ligados e se implicam mutuamente; a língua é necessária para que a fala seja inteligível e produza todos os seus efeitos; mas esta é necessária para que a língua se estabeleça; historicamente, o fato da fala vem sempre antes. Como se imaginaria associar uma ideia a uma imagem verbal se não se surpreendesse de início essa associação num ato de fala? Por outro lado, é ouvindo os outros que aprendemos a língua materna; ela se deposita em nosso cérebro somente após inúmeras experiências. Enfim, é a fala que faz evoluir a língua: são as impressões recebidas ao ouvir os outros que modificam nossos hábitos linguísticos. Existe, pois, interdependência da língua e da fala; aquela é ao mesmo tempo o instrumento e o produto desta. Tudo isso, porém, não impede que sejam duas coisas absolutamente distintas. (SAUSSURE, 2012, p. 51, grifos nossos).

Ao afirmar que "o fato da fala vem sempre antes", Saussure admite que é por meio da fala, ato concreto, psicofísico, que nós, seres humanos, entramos em contato com a língua; ao ouvirmos o outro falando é que aprendemos a língua, assimilamos o sistema. Se a língua "se deposita em nosso cérebro após inúmeras experiências", é impossível concebê-la sem a participação dos sujeitos, sem a inter-relação entre eles. $\mathrm{O}$ ato individual da fala, segundo Saussure, é o embrião da linguagem.

$\mathrm{O}$ ato de fala, em uma dinâmica de troca, instaura a experiência humana inscrita na linguagem. É justamente essa inter-relação entre os sujeitos que está na base do princípio de subjetividade de Benveniste (1995, p. 285):

Não atingimos nunca o homem separado da linguagem e não o vemos nunca inventando-a. Não atingimos jamais o homem reduzido a si mesmo e procurando conceber a existência do outro. É um homem falando que encontramos no mundo, um homem falando com outro homem, e a linguagem ensina a própria definição do homem.

Benveniste conceitua a "subjetividade" como a capacidade do locutor para se propor como "sujeito". Explica que não se trata do sentimento que cada indivíduo experimenta de ser ele mesmo, mas da "unidade psíquica que transcende a totalidade das experiências vividas que reúne, e que assegura a permanência da consciência”. É a emergência no ser de uma propriedade fundamental da linguagem. Afirma Benveniste (1995, p. 286, grifos do autor): “É 'ego' quem diz ego. Encontramos aí o fundamento da 'subjetividade' que se determina pelo status linguístico da 'pessoa". 
Mas a tomada de consciência de si mesmo, de sua individualidade, só pode ocorrer em uma relação de alteridade, em que o uso do "eu" pressupõe a existência de um outro, o "tu". Para Benveniste (1995), o $e u$ refere-se ao ato de discurso individual no qual é pronunciado, designando o locutor. É um termo que só pode ser identificado dentro da instância de discurso, que só tem referência atual, ou seja, fora do discurso, eu não significa nada, é uma forma vazia. E a realidade à qual ele remete é a realidade do discurso.

A linguagem só é possível porque cada locutor se apresenta como sujeito, remetendo a ele mesmo como $e u$ no seu discurso. Por isso, eu propõe outra pessoa, aquela que, sendo embora exterior a "mim", torna-se o meu eco - ao qual digo tu e que me diz tu. (BENVENISTE, 1995, p. 286).

As formas linguísticas $e u$ e $t u^{4}$, indicadoras da pessoa do discurso, são complementares, pois uma não se concebe sem a outra. Essa condição de diálogo estabelecida pela relação $e u$-tu é constitutiva da subjetividade. E a inversibilidade desse processo é que possibilita a comunicação humana, como bem explicam Flores e Teixeira (2005, p. 33):

O fundamento da subjetividade é dado pela categoria de pessoa presente no sistema da língua mediante determinadas formas (o pronome "eu", por exemplo). Vale lembrar, porém, que essa subjetividade é dependente da inversibilidade aludida quando do tratamento do par "eu/tu". Essa inversibilidade assegura a intersubjetividade sem a qual não faz sentido falar de categoria linguística de pessoa.

Aquele que fala se refere a ele mesmo sempre pelo indicador $e u$. Este ato do discurso que enuncia $e u$, para aquele que enuncia, mesmo que repetido milhares de vezes, constituirá sempre um ato novo, porque ele realiza a cada vez a inserção do locutor em dado momento e circunstância, sempre únicos. Assim, o eu na

4. Na definição de Benveniste (1995, p. 279), eu é o "indivíduo que enuncia a presente instância de discurso que contém a instância linguística $e u$ ", e tu é o "indivíduo alocutado na presente instância de discurso contendo a instância linguística tu”. Ou seja, eu e tu são entendidos como categorias da linguagem, podendo aparecer no discurso de forma explícita ou permanecer implícitas. Definem-se na própria instância de discurso e referem a uma realidade distinta a cada vez que são enunciados. Já o ele, a *não pessoa, pertence ao nível sintático e tem por função combinar-se com uma referência objetiva, independentemente da instância enunciativa que a contém. 
comunicação muda alternativamente de estado: aquele que o entende o relaciona ao outro que fala, porém, ao falar, assume eu por sua própria conta.

Uma dialética singular é a mola desta subjetividade. A língua provê os falantes de um mesmo sistema de referências pessoais de que cada um se apropria pelo ato de linguagem e que, em cada instância de seu emprego, assim que é assumido por seu enunciador, se torna único e sem igual, não podendo realizar-se duas vezes da mesma maneira. (BENVENISTE, 1989, p. 69).

O principal ponto de apoio para a marcação da subjetividade são os pronomes pessoais, dos quais dependem os indicadores da dêixis, os demonstrativos, os advérbios, os adjetivos, que organizam as relações de espaço e tempo em torno do sujeito tomado como ponto de referência.

Na perspectiva adotada por Benveniste (1989), a linguagem está de tal maneira organizada que possibilita a cada locutor apropriar-se da língua toda designando-se como eu. $\mathrm{O}$ eu, que nas formas da língua não é senão um pronome, um item lexical semelhante a qualquer outro, uma vez posto em ação no discurso, introduz a presença da pessoa, sem a qual a linguagem seria impossível.

\section{DA CONSTRUÇÃo DE SENTIDO NA LINGUAGEM}

Benveniste estabelece uma distinção entre forma e sentido, entre dois modos de significação: o semiótico e o semântico. O artigo "A forma e o sentido na linguagem" (1967) aborda essa questão.

O signo, definido como unidade semiótica, é dotado de significação na comunidade daqueles que fazem uso de uma língua. A totalidade desses signos constitui a totalidade da língua, ou seja, o sistema linguístico, a forma, cuja função é significar.

Cada signo entra numa rede de relações e de oposições com os outros signos que o definem, que o delimitam no interior da língua. Quem diz "semiótico" diz "intralinguístico". Cada signo tem de próprio o que o distingue dos outros signos. Ser distintivo e ser significativo é a mesma coisa. (BENVENISTE, 1989, p. 227-228, grifos do autor).

O primeiro modo de significação, portanto, o semiótico, corresponde ao nível "intralinguístico", em que cada signo é distintivo, significativo em relação aos 
demais, dotado de valores opositivos e genéricos e dispostos em uma organização paradigmática. Aqui, a relação do signo com as coisas denotadas não interessa, tampouco a relação da língua com o mundo (FLORES; TEIXEIRA, 2005).

Já a frase, entendida como expressão semântica por excelência, tem a função de comunicar pela linguagem posta em ação, na mediação entre os homens, entre os homens e o mundo, transmitindo informação, comunicando experiência, enfim, organizando a própria vida em sociedade. Diz Benveniste (1989, p. 229): "Não se trata mais, desta vez, do significado do signo, mas do que se pode chamar o intencionado, do que o locutor quer dizer, da atualização linguística de seu pensamento". E ainda:

O sentido da frase é de fato a ideia que ela exprime; este sentido se realiza formalmente na língua pela escolha, pelo agenciamento de palavras, por sua organização sintática, pela ação que elas exercem umas sobre as outras. Tudo é dominado pela condição do sintagma, pela ligação entre os elementos do enunciado destinado a transmitir um sentido dado, numa circunstância dada. (BENVENISTE, 1989, p. 230).

Assim, o segundo modo de significação, o semântico, resulta da atividade do locutor que coloca a língua em ação. Aqui, o critério usado é o da comunicação para definir a palavra como unidade de operações sintagmáticas que se realizam no nível da frase (FLORES; TEIXEIRA, 2005).

Enquanto o semiótico é uma propriedade da língua, o semântico é o sentido construído pelo locutor que emprega a língua, é a ideia que ele expressa, servindo-se de palavras integrantes de sintagmas particulares, em suas relações sintagmáticas. Podese dizer, então, que o valor semântico é resultado da articulação entre relações paradigmáticas e sintagmáticas. Nessa perspectiva, a forma e o sentido, ou seja, o semiótico e o semântico se articulam e convergem para a construção do sentido no uso da língua.

\section{Da leitura COMO ATO ENUNCIATIVO}

No artigo "O aparelho formal da enunciação", de 1970, Benveniste propõe-se a analisar o emprego da língua, distinguindo-o do emprego das formas, ou seja, da língua estudada somente sob o ângulo da nomenclatura morfológica e gramatical. Nessa nova perspectiva apontada por Benveniste, a noção de enunciação, entendida como uso da língua, pressupõe um quadro enunciativo constituído pela noção de pessoa $(e u / t u)$ e a situação de uso (o espaço e o tempo). 
Benveniste (1989, p. 82) conceitua a enunciação como o processo de "colocar em funcionamento a língua por um ato individual de utilização". É o ato mesmo de produzir o enunciado que se torna objeto de estudo, e não o texto do enunciado. O locutor utiliza a língua como instrumento para se enunciar e produzir o discurso, ou seja, pela enunciação, a língua é convertida em discurso.

$\mathrm{O}$ ato individual pelo qual se utiliza a língua introduz em primeiro lugar o locutor como parâmetro nas condições necessárias da enunciação. Antes da enunciação, a língua não é senão possibilidade da língua. Depois da enunciação, a língua é efetuada em uma instância de discurso, que emana de um locutor, forma sonora que atinge um ouvinte e que suscita uma outra enunciação de retorno. (BENVENISTE, 1989, p. 84).

A instância de discurso a que se refere Benveniste é o ato de dizer, cada vez único, pelo qual a língua é atualizada em fala pelo locutor. De acordo com o Dicionário de Linguística da Enunciação:

Ao apropriar-se do aparelho formal da enunciação, o locutor produz uma referência única e irrepetível, permitindo a semantização da língua. Tal movimento faz emergir os índices de pessoa (a relação eu-tu), os índices de ostensão (este, aqui) e as formas temporais, produzidas na e pela enunciação. (FLORES et al., 2009, p. 48).

A temporalidade da instância de discurso contém os indicadores de subjetividade, ou seja, o tempo da instância de discurso é o momento sempre presente em que o eu enuncia, mesmo que fale de acontecimentos do passado ou futuros. Ela se identifica com o tempo presente do locutor, e não com o presente formal gramatical. É o espaço-tempo da atualização da forma linguística eu, o aqui-agora, que também marca a passagem de locutor a sujeito.

Ao enunciar, o eu apropria-se da língua, declarando-se locutor e implantando o outro diante de si, independentemente do grau de presença que atribua a este outro. Assim, toda enunciação corresponde a uma alocução, postulando um alocutário, o tu. A relação discursiva com o outro, seja real ou imaginário, individual ou coletivo, caracteriza a enunciação:

Esta característica coloca necessariamente o que se pode denominar o quadro figurativo da enunciação. Como forma de discurso, a enunciação coloca duas "figuras" 
igualmente necessárias, uma, origem, a outra, fim da enunciação. É a estrutura do diálogo. Duas figuras na posição de parceiros são alternativamente protagonistas da enunciação. Este quadro é dado necessariamente com a definição da enunciação. (BENVENISTE, 1989, p. 87).

Esse modelo teórico dá conta ainda do processo de referenciação como parte integrante da enunciação. Mas a referência de que fala Benveniste não é a referência ao mundo, ela diz respeito à enunciação, ao ato individual de utilização da língua. Ao se apropriar da língua, o locutor estabelece relação com o mundo a partir do discurso de um sujeito, enquanto o alocutário correfere:

Por fim, na enunciação, a língua se acha empregada para a expressão de uma certa relação com o mundo. A condição mesma dessa mobilização e dessa apropriação da língua é, para o locutor, a necessidade de referir pelo discurso, e, para o outro, a possibilidade de co-referir identicamente, no consenso pragmático que faz de cada locutor um co-locutor. A referência é parte integrante da enunciação. (BENVENISTE, 1989, p. 84).

Tomando a noção de aparelho formal da enunciação, entendido como um dispositivo comum a todos os idiomas e disponibilizado pela própria estrutura da língua para que o locutor atualize o sistema a fim de propor-se como sujeito, é possível pensar a leitura como um ato enunciativo. É o que tentamos explicar a seguir.

Na produção de um discurso escrito (texto), o autor/locutor ${ }^{5}$ apropria-se do aparelho formal da língua e, através de operações paradigmáticas e sintagmáticas, enuncia-se, produzindo um discurso situado no espaço-tempo, no aqui-agora, cujas marcas linguísticas são reveladoras da subjetividade desse sujeito.

Nesse processo de apropriação, ocorre a tomada, por inteiro, da língua. O autor/ locutor estabelece relações com as formas da língua e seleciona as que forem compatíveis com a ideia a ser expressa. Na seleção, está implícita a própria estrutura da língua, com as normas que regem sua morfologia e sintaxe. A língua, ao ser posta em funcionamento pelo autor/locutor por meio da enunciação, é automaticamente atualizada na instância do discurso, passando a ter existência e a constituir sentido. O sentido, por sua vez, é relativo à instância do discurso em que o autor/locutor

5. Utilizamos as expressões autor/locutor e leitor/locutor com a finalidade de melhor explicitar as figuras enunciativas envolvidas, respectivamente, no processo de produção e de leitura do texto escrito. 
enuncia, ou seja, tem referência única, ligada a eu-tu-aqui-agora, indicadores das categorias de pessoa, espaço e tempo em que o enunciado foi produzido.

A relação do autor/locutor com a língua também determina os caracteres linguísticos da enunciação. De acordo com Benveniste (1989, p. 86), “[...] a enunciação fornece as condições necessárias às grandes funções sintáticas. Desde o momento em que o enunciador se serve da língua para influenciar de algum modo o comportamento do alocutário, ele dispõe para este fim de um aparelho de funções”. Nesse sentido, pode-se dizer que toda enunciação pressupõe uma intencionalidade por parte do autor/locutor, de modo a influenciar o comportamento do alocutário/leitor através do uso das funções sintáticas fornecidas pela língua, como as formas de interrogação, de intimação, de asserção, todos os tipos de modalidades formais pertencentes aos verbos, à fraseologia, indicando incerteza, possibilidade, indecisão, etc.

O leitor, por sua vez, no encontro com o discurso (texto), percebe as marcas linguísticas deixadas pelo autor/locutor e atribui sentido a elas. Mais do que constituir sentidos, a leitura é um processo de reconstituição de sentidos, ou seja, em um percurso inverso ao executado pelo autor/locutor, o leitor reconhece a língua como um sistema de signos distintivos e interpreta as escolhas lexicais e os arranjos sintagmáticos realizados pelo locutor do enunciado.

Nessa perspectiva, deve-se considerar que o leitor se depara com um discurso oriundo de uma relação eu-tu-aqui-agora; portanto, o sentido reconstituído no ato de leitura pode não condizer com as representações daquele que produziu o texto. No processo de reconstrução de sentidos, instaurado pela leitura, o leitor produz um discurso único e irrepetível, situado num espaço-tempo, num aqui-agora, alheio ao espaço-tempo em que o discurso lido foi escrito.

De alocutário, o leitor passa a locutor, porque, ao enunciar, cria possibilidades de atualização do sistema linguístico que podem não coincidir com as previstas pelo autor/locutor. Na instância de discurso engendrada pela leitura, o leitor/locutor reverte-se no $e u$, enunciando-se por meio de um discurso único, instaurado por cada nova leitura.

A reversibilidade da relação $e u$-tu é fundamental para entender essa questão. Como explica Benveniste (1995, p. 281): "É identificando-se como pessoa única pronunciando eu que cada um dos locutores se propõe alternadamente como 'sujeito'. Assim, o emprego tem como condição a situação de discurso e nenhuma outra”. Essa característica do sistema fundamenta o discurso individual, em que cada locutor assume por sua conta a língua inteira. De posse do discurso escrito, a figura 
do autor já não tem mais relevância, pois a relação de diálogo se estabelece agora entre o leitor/locutor e o locutor do enunciado, figuras enunciativas.

Considerando, pois, a leitura como um ato de enunciação, de colocação da língua em uso, pode-se dizer que o leitor assume a posição de locutor, já que, ao ler e reconstituir sentidos, ele instaura o interlocutor, o espaço e o tempo na produção de um novo discurso, caracterizado pelas marcas de sua subjetividade. No ato da leitura, a subjetividade apresenta-se, portanto, como a capacidade do leitor/locutor de apropriar-se da língua e atualizá-la, posicionando-se no discurso como sujeito que diz eu.

\section{CONSIDERAÇões Finais}

Pensar a leitura sob a perspectiva enunciativa significa opor-se à concepção instrumental da linguagem, concebida como simples codificação de uma realidade exterior, que restringe a leitura à tarefa de decodificação ou de decifração do texto. A leitura constitui antes uma atividade de percepção e interpretação dos signos linguísticos que se sucedem de forma ordenada, guardando entre si relações de sentido. Ler é perceber a associação lógica das palavras, o encadeamento das frases e parágrafos, as marcas linguísticas do enunciador, na tentativa de reconstituir os sentidos de um enunciado produzido em uma determinada instância de discurso.

Isso implica considerar também que o texto não é uma estrutura fechada e acabada, mas é passível de ser compreendido e interpretado por um outro, que não o seu autor. O leitor, nesse caso, ao reconstituir os sentidos do texto, apropria-se dele, atualiza-o, assimilando as intenções do autor e relacionando o que foi apreendido com seus conhecimentos prévios, atribuindo ao texto uma nova existência e impregnando-o com as características de sua subjetividade. O texto configura-se, então, como possibilidade de diferentes leituras. Isso explica por que nenhuma leitura é igual à outra, pois se trata da produção de um discurso singular em uma instância eu-tu-aqui-agora, única e irrepetível.

Conceber a leitura como um ato enunciativo é, enfim, reconhecer a atividade do leitor que, ao fazer uso da língua, produz a cada vez novos sentidos, enuncia-se e, assim, institui-se como sujeito, ao mesmo tempo em que institui o outro diante de si. A chave desse processo é a própria linguagem, que está na natureza do homem e funda a experiência subjetiva dos sujeitos. 


\section{REFERENCIAS}

BENVENISTE, Émile. Problemas de linguística geral I. Campinas, SP: Pontes, 1995. . Problemas de linguística geral II. Campinas, SP: Pontes, 1989.

FLORES, Valdir do Nascimento. Introdução à teoria enunciativa de Benveniste. São Paulo: Parábola, 2013. FLORES, Valdir do Nascimento; BARBISAN, Leci Borges. Sobre Saussure, Benveniste e outras histórias da linguística. Apresentação. In: NORMAND, Claudine. Convite à linguística. Org. de Valdir do Nascimento Flores e Leci Borges Barbisan. São Paulo: Contexto, 2009. p. 7-22.

FLORES, Valdir do Nascimento; TEIXEIRA, Marlene. Introdução à linguística da enunciação. São Paulo: Contexto, 2005. . Saussure, Benveniste e a teoria do valor: do valor e do homem na língua. Letras \& Letras, Uberlândia, n. 25, jan./jun. 2009, p. 73-84. Disponível em: <http://www.lume.ufrgs.br/bitstream/ handle/10183/104943/ooo939270.pdf?sequence=1>. Acesso em: 19 jul. 2016.

FLORES, Valdir do Nascimento et al. Dicionário de linguística da enunciação. São Paulo: Contexto, 2009. Disponível em: <https://ucsvirtual.ucs.br>. Acesso em: 19 jul. 2016.

NORMAND, Claudine. Saussure-Benveniste. In: . Convite à linguística. Org. de Valdir do

Nascimento Flores e Leci Borges Barbisan. São Paulo: Contexto, 2009. p. 197-204. SAUSSURE, Ferdinand de. Curso de linguística geral. 28. ed. São Paulo: Cultrix, 2012.

\section{SOBRE A AUTORA:}

Carina Fior Postingher Balzan é graduada em Letras - Língua Portuguesa (Universidade de Caxias do Sul), tem Mestrado em Letras e Cultura Regional (Universidade de Caxias do Sul) e está cursando Doutorado em Letras (Universidade de Caxias do Sul/Centro Universitário Ritter dos Reis). É professora do Instituto Federal de Educação, Ciência e Tecnologia do Rio Grande do Sul - Câmpus Bento Gonçalves. Tem experiência na área de Língua Portuguesa e Literatura, com pesquisa nos seguintes temas: leitura, formação de leitores e práticas culturais.

E-mail: cfpbalzan@gmail.com 